\title{
A Cohort Analysis on the Career Life Cycles of Players of the LPGA of Japan Tour
}

\author{
Eui Hang Shin ${ }^{1,2}$ (D) \\ Received: 18 July 2020 / Accepted: 30 November 2020/ Published online: 25 January 2021 \\ (C) The Author(s), under exclusive licence to Springer Nature B.V. part of Springer Nature 2021
}

\begin{abstract}
The purpose of this study is to investigate the patterns of professional career paths of the players of the Ladies Professional Golf Association of Japan (JLPGA) Tour. Using the athletes' professional career life cycle model as the theoretical framework, this study will analyze the career development of elite players of the JLPGA from their rookie year to the point of retirement. The year of each JLPGA tournament win by selected players will be examined for the players' entire careers. The players' money ranking for each year of their careers is also analyzed to determine the stages of the players' career life cycles. The tournament win span, i.e., the number of years between a player's first and last JLPGA tournament win, will be computed. The career life cycles of players of different cohorts will be compared to determine whether or not there was any transformation in the structure of career stages of the players over time. The career development patterns of Japanese-born players will be compared with those of the international players of the JLPGA.
\end{abstract}

Keywords Professional career life cycle stages $\cdot$ A cohort analysis $\cdot$ Female professional athletes $\cdot$ LPGA of Japan Tour $\cdot$ International players

\section{Introduction}

The notion of career life cycle stages has been investigated from diverse disciplinary perspectives. In the field of management science, Super reviewed the career development of workers in the labor market and formulated five career development stages: growth, exploration, establishment, maintenance, and disengagement [1]. Studies in the field of human resource management have reported six stages of an employee career

Eui Hang Shin

kenshin@snu.ac.kr

1 Asia Center, Seoul National University, Seoul, South Korea

2 Department of Sociology, University of South Carolina, Columbia, SC, USA 
life cycle: attraction, recruitment, onboarding, development, retention, and separation [2]. Over the past 50 years, researchers in the field of sport management, sport psychology, and sport sociology have adopted and modified the traditional stage theory and applied it to sporting careers [3-6].

Previous studies have defined an athletic career as "a succession of stages such as the initiation/sampling stage, development/specialization stage, perfection/mastery/investment stage, final/maintenance stage, and discontinuation stage of competitive sport involvement" [7]. Wylleman et al. developed a life span model around a series of predictable transitions through athlete's careers [6]. These are regarded as normative transitions as part of a universal sequence-related biological, social, and emotional events which occur across a life span [6]. Non-normative transitions result from important events that take place which require a response from the athlete, thus are involuntary, for instance, trade to another team, injury, and others [6]. Savickas [8] and Brott [9] asserted that individuals experience many changes in their career paths and today's careers are "boundary less" and emphasized the importance of personal meaning given to career, personal goals, preferences, and interests.

Stambulova et al. have documented the evolution in athletic career development and transition research from a focus on "athletic retirement and nonathletic frameworks" until the 1980 s to a shift to "a whole career, a whole person, and a whole environment perspective" in recent years [10]. Henriksen et al. reported that the athletic talent development environment model was effective in explaining the development of athletes in track and field, swimming, cycling, soccer, and handball, into elite level athletes, but in contrast, in golf, despite resources, progression to elite level athletes was not evident [11].

A close review of previous studies on the athletic career life cycles revealed that there still exist a number of gaps in the body of knowledge on the topics [12, 13]. First, previous studies on athletic career life cycles have focused primarily on career transition, especially the transition from sporting to non-sporting careers after an athlete's retirement from a competitive sport. Various aspects of this transition are very important to understand in order to offer effective guidance and support to athletes for their post-playing career. However, it is also essential to conduct an inclusive investigation on the development and transition of an athlete's career as a whole as well as withincareer stage transition from the initiation to the discontinuation stage. Second, the career stage models stipulated a linear transition from one stage to the next, and thus overlooking the nonlinear, frequent fluctuations in career paths. Third, although the career stage models have been transformed over the years, the conceptual frameworks are still descriptive, not being sufficiently explanatory. Fourth, the applications of the athletic career stage models have been centered on the European and North American cases. A limited number of empirical studies have been conducted on elite athletes in the Asian region, especially among elite women athletes in Asia. Fifth, previous studies have not paid a sufficient amount of attention to the fact that professional athletes are self-employed or independent contractors and their career life cycle stages may be substantially different from those of the employees in bureaucratic organizations [14-16]. This point is elaborated in the following section.

The Characteristics of Athletic Career Life Cycles Athletic career life cycle tends to manifest several important characteristics. First of all, elite professional athletes who compete at the highest level tend to start their sport at a fairly young age and compete 
continuously in that sport through their primary, secondary, and tertiary schooling. It is not unusual to find many elite athletes who started to play their chosen sport at age 6 or 7. Second, the odds of becoming a player in a major professional sports league are extremely low. According to the NCAA findings for the 2018-2019 period, the probability of college players being drafted by the NBA, WNBA, and NFL was $1.2 \%, 0.8 \%$, and $1.6 \%$, respectively. ${ }^{1}$ Third, the average length of professional athlete playing careers is extremely short compared to non-sports careers. The average playing career length for the National Football League is only 3.3 years. The average career length varies by the player's position: the career length for running backs, wide receivers, corner backs, quarterbacks, and kickers was 2.57, 2.81, 2.94, 4.44, and 4.87 years, respectively. ${ }^{2}$

Fourth, a professional athlete's career tends to involve a substantial amount of uncertainty due to the risk of injuries. The injury rate for the NFL was 75.4 per 1000 "athlete-exposures," while the corresponding rate for the NBA, MLB, NHL, and UEFA was $19.1,15.5,15.6$, and 18.3, respectively. ${ }^{3}$ Golf, as a noncontact sport, has not been recognized as a sport associated with injuries. However, epidemiologic studies reported that professional golfers suffer injuries to the wrist and lower back, nearly two serious injuries per player during their career [17-19]. Fifth, many professional athletes in non-team sports such as golf and tennis are independent and self-employed, and their earnings are largely dependent upon their performance and the prize money they win in each event.

Sixth, the pool of competition in some professional sports is completely open, with rookies playing against top-ranked players in tournaments. This is the case for the PGA, LPGA, ATP, and WTA tours. In fact, the top-seeded player plays against the lowest ranked player in the match play format tournaments of the tours of PGA and LPGA. By contrast, competition for upward mobility in typical bureaucratic organizations tends to be within the pools of individuals with the same rank and class. Seventh, some elite professional athletes have the opportunities to generate income through product endorsement and advertisements. However, only the top star players have such opportunities for extra income. Eighth, unlike most team sports where the games are played on a home-or-away basis, tournaments of the PGA, LPGA, ATP, WTA, and other individual competitive sports are held at designated sites away from the player's home base. Players of such professional sports are labeled touring professionals, and the frequent and long-distance travel required of them has significant implications for players' lifestyles and career durability.

Ninth, unlike in team sports, professional tour players are responsible for scheduling and carrying out their own physical training and practice and lessons with personal coaches, and making travel arrangements. More importantly, such players make their own final decisions on playing strategy, such as what types of shots to hit. Hence,

\footnotetext{
${ }^{1}$ Source: http://www.ncaa.org/about/resources/research/estimated-probability-competing-professionalathletics

${ }^{2}$ Source: https://www.statista.com/statistics/240102/average-player-career-length-in-the-national-footballleague/

${ }^{3}$ Source: https://nflinjuryanalytics.com/2017/06/06/just-how-dangerous-is-the-nfl-vs-other-sports/: "The 'athlete-exposure' (AE) is simply defined as 1 athlete participating in a practice or, in the case of this article, a game. Thus, a single NFL game where every available player plays in the game would count for 92 athlete exposures - the 46 guys on the active game day roster on each of the two teams."
} 
touring professionals are directly accountable for their own success and failure in terms of athletic performance. Professional golf and tennis players do not have teammates, coaching staff, scouts, medical staff, general managers, and team owners to lean on. In light of the above distinctions, one must employ a holistic approach in analyzing athletes' career life cycles by examining all career stages from initiation to discontinuation stages, paying special attention to the unique characteristics of the social structures of athletes' professional careers.

\section{Purpose of the Study}

The purpose of this study is to investigate the patterns of the professional career paths of the players of the Japan Ladies Professional Golf Association (JLPGA). Using the professional career life cycle model as the theoretical framework, this study will analyze the career development of elite players of the JLPGA from their rookie year to retirement. The year of each JLPGA tournament win by selected players will be examined for the players' entire careers. The players' money ranking for each year of their careers is also analyzed to determine the stages of the players' career life cycles. The tournament win span - the number of years between the first and the last JLPGA tournament win - of the players' careers will be computed. The career paths of players of different cohorts will be compared to determine whether or not there was any transformation in the structure of players' career stages over time. The patterns of career development of Japanese-born players will also be compared with those of international players of the JLPGA Tour.

\section{The Golf Industry in Japan [20, 21]}

The game of golf was introduced to Japan by Arthur Hesketh Groom, a British expatriate, who constructed the Kobe Golf Club in 1903 [20, 21]. Playing golf was initially limited to foreign elites and then shifted gradually to include Japanese elites [22]. Golf continued to diffuse from the highest status group to the next highest social class groups in Japanese society [20, 21]. Until the end of World War II, golf remained a part of only the privileged classes' lifestyles [21]. Along with the rapid economic development in the post-war era, the new middle class emerged and the golf industry grew rapidly, with increasing demand for golf as one of the major leisure activities of high-salaried business. The Japanese golf industry went through consecutive golf boom periods between the1960s and the early 1980s, with the number of golf courses and the size of the golf-playing population increasing at an unprecedentedly rapid pace. The growth history of the golf industry in Japan continued to fit the trickle-down model [21]. That is, golf diffused by crossing social classes, from the upper class to the upper middle, and to the middle class, and shifted from exclusively male participation to the inclusion of women players. In fact, females comprised nearly $20 \%$ of Japanese golfers by the early 1990s [21]. Women's sudden interest in golf "re-framed the game as part of the courtship process with (upwardly mobile) men, and hence, a new opportunity for women to dress up in a completely different set of (adorable) clothing, which they would need to go out and buy [21]." 
Since its introduction, golf has been regarded as the ultimate status symbol: being able to play golf means that you "ha[ve] made it." "The blessing of the bubble economy of the late 1980s and the social status attached to playing golf resulted in an exponential expansion of the golf industry in Japan. ${ }^{5}$ The number of rounds played increased from 10 million in 1963 to 102 million in $1992 .^{6}$ The number of courses increased from 387 to more than 2000 during the same period. ${ }^{7}$ However, the bubble economy went bust by 1992 , and the economic downturn had a profound impact on the Japanese society including the golf industry. During an 11-year span from 1992 to 2002, rounds played fell from 102 million to 88 million. About 1700 - or 71\% — of Japan's 2460 courses are in financial trouble. ${ }^{8}$ Of those, 450 have declared bankruptcy and another 200 have been acquired. ${ }^{9}$ In addition, the 2008-2009 global recession was a big blow to the already suffering golf industry in Japan. The Japanese economy started to recover from a nearly decade-long slump by 2015 , and the golf industry has been bouncing back in recent years. ${ }^{10}$ The economic downturn had forced private golf clubs to lower their club membership initiation and green fees substantially, and such actions made playing golf more affordable than ever before. Ironically, that may have expanded the pool of potential players by raising the interest level in golf among average salary workers. However, consistent with the rest of the world, Japan has seen a decline in golf's popularity among young generations. ${ }^{11}$

The Ladies Golf Association of Japan (JLPGA) Previous studies asserted that the development of women's sports in Japan was correlated with the expansion of liberal education [23, 24]. Ikeda pointed out that women's physical education was first introduced after the Sino-Japanese War of 1894-1895 to support the Japanese state's notion of liberal education and maternal feminism [23]. Ikeda also indicated that the liberal education programs produced many "haikara" (high-collar) or "new women" and the women's participation in organized and competitive sports started to rise [23]. Raita reported that the introduction of Western sports to Japanese women and the first competitive athletic meeting exclusively for Japanese women occurred much later than those for men as in the cases of North America and Europe [25]. The first Japan Open Golf Championship (for men) was held in 1927, while the first Japan Women's Open Golf Championship took place nearly 41 years later in $1968 .^{12}$ The first Japan Women's Professional Golf Championship tournament was also held in 1968.

The first ever competitive golf tournament for women in Japan was the National Golf Championship of Women Employees of Golf Courses in 1961, in which 28 players participated. ${ }^{13}$ The participants in that tournament were mostly women caddies

\footnotetext{
${ }^{4}$ Source: https://golfweek.usatoday.com/2004/05/08/2004-rise-and-fall-golf-japan/

${ }^{5}$ Source: https://golfweek.usatoday.com/2004/05/08/2004-rise-and-fall-golf-japan/

${ }^{6}$ Source: https://golfweek.usatoday.com/2004/05/08/2004-rise-and-fall-golf-japan/

${ }^{7}$ Source: https://golfweek.usatoday.com/2004/05/08/2004-rise-and-fall-golf-japan/

${ }^{8}$ Source: https://golfweek.usatoday.com/2004/05/08/2004-rise-and-fall-golf-japan/

${ }^{9}$ Source: https://golfweek.usatoday.com/2004/05/08/2004-rise-and-fall-golf-japan/

${ }^{10}$ Source: https://www.golfadvisor.com/articles/japan-golf-courses-culture-2020-olympics-zozo-skins-game

${ }^{11}$ Source: https://www.marketwatch.com/story/death-watch-how-much-longer-can-golf-survive-2017-04-18; https://bleacherreport.com/articles/648286-decline-of-golf-in-america-worklife-balance-is-the-true-culprit; https://www.goodnet.org/articles/japan-turning-golf-courses-into-solar-farms

12 Source: Jgto.org; lpga.or.jp.

${ }^{13}$ Source: https://www.lpga.or.jp/about/history/.
} 
who worked at different golf courses [7, 26, 27]. ${ }^{14}$ The Japan Golf Association (JGA), which became the organizational origin of the JGTO, created the "Women's Division" within the JGA in $1967 .{ }^{15}$ The Japan Ladies Professional Association was formally organized in $1974 .{ }^{16}$ JLPGA adopted the tour system (LPGA of Japan Tour) in $1988 .{ }^{17}$ Over the past three decades, the JLPGA Tour has been steadily internationalized in terms of both the composition of the players on the tour and the movement of players to the LPGA Tour for international competition outside Japan. For the 2020 season, 17 of 65 players on the priority list were internationals. ${ }^{18}$ Historically, several elite players of the JLPGA Tour had competed internationally and compiled numerous tournament wins. The major accomplishments of JLPGA players in international competitions are as follows: (1) Hisako Higuchi won the 1977 LPGA Championship, and she was inducted to the World Golf Hall of Fame in 2003; (2) Ayako Okamoto won 17 tournaments on the LPGA tour during the 19821992 period, and in 1987, she became the first international player to win the money winner title of the LPGA and was inducted into the World Golf Hall of Fame in 2005; (3) Ai Miyazato had 9 career victories on the LPGA Tour during the 2006-2017 period, and she was ranked number 1 in the Women's World Golf Rankings in 2010; and (4) Hinako Shibuno won the 2019 Women's British Open. ${ }^{19}$

The JLPGA Tour is recognized as the second most lucrative women's professional golf tour in the world with a total purse of 3.935 billion yen ( $\$ 36.54$ million) and 37 official events for the 2020 season. $^{20}$ The LPGA had scheduled 33 official events in 11 different countries with the total purse of $\$ 75.1$ million for the 2020 season. $^{21}$ The total purse of the PGA Tour was $\$ 430.50$ million with nearly 50 official events for the 2020 season. $^{22}$ In comparison, the total purse of the JGTO (Japan Golf Tour Organization), a men's professional golf tour of Japan, was $\$ 30.26$ million with 25 official events for the 2020 season. ${ }^{23}$ Substantial portions of scheduled tournaments of these professional golf tours in Japan and the USA have been already canceled or rescheduled due to the coronavirus pandemic. However, it is important to note that the nature of gender inequality in the amount of the total purse of the tours is different between Japan and the USA. The PGA Tour's purse is more than six times greater than that of the LPGA. On the other hand, the JLPGA Tour had \$6 million more in its total purse and 12 more official events than the JGTO had for the 2020 season. $^{24}$

\footnotetext{
${ }^{14}$ Historically, people of wealth played golf both for pleasure and as means of becoming a member of elite group in the society. On the other hand, the early professional golfers were from working class and started their careers as caddies. Bourdieu analyzed the dynamic interplay between social class and sport and his conceptual framework became an important benchmark in the sociological study of sports.

${ }^{15}$ Source: www.lpga.or.jp.

${ }^{16}$ In comparison, the Ladies Professional Golf Association (LPGA) of the USA was founded in 1950.

${ }^{17}$ Source: www.lpga.or.jp

${ }^{18}$ Source: "2020 Season JLPGA Tour Eligibility Priority List” (lpga.or.jp).

${ }^{19}$ Sources: www.lpga.or.jp

${ }^{20}$ Source: www.lpga.or.jp

${ }^{21}$ Source: www.lpga.com

${ }^{22}$ Source: www.pga.com

23 Source: www.jgto.org

${ }^{24}$ Japan is not alone in that respect. The KPGA Tour, men's professional golf tour in Korea, showed 17 official events for total prize money of $\$ 11.90$ million, while the KLPGA, the women's tour, scheduled 31 official tournaments with a total purse of $\$ 21.93$ million for the 2020 season. The Korean media used the term of "female high, male low" phenomena referring to this gender inequality in the Korean professional golf tours. It has been rumored that corporations tend to select players for endorsement contracts on the basis of their physical attractiveness rather than their records of performance. (www.kpga.com; www.klpga.co.kr; www.golfdigest.com/article/View, 2.27.2019).
} 
The fact that the women's tour in Japan has a bigger purse and more tournaments than the men's may reflect the difference between the tours in popularity among Japanese golf fans. The total purse of a tour is largely determined by contributions from major corporate sponsors. A corporation's decision on its sponsorship amount and which tour it sponsors will be based on the expected return on investment. ${ }^{25}$ And market research on consumer preferences will influence those corporate sponsorship decisions. ${ }^{26}$ Some pundits argue that sexism is the underlying cause of the reverse gender discrimination in the Japanese golf industry. The assumption is that Japanese sports fans tend to enjoy watching physically attractive young female golfers on television and that corporate sponsors take into account such fan preferences. ${ }^{27}$ Such a tendency may lead to the exploitation of sexual attractiveness to the detriment of the core values of the sport. Given that professional sports have become increasingly commercialized and entertainment-oriented, sport organizations must address the possible long-term effects of such tendencies on the development of their sports.

\section{Analysis}

The data used in this study are drawn from the archives of the JLPGA Tour (lpga.or.jp). The statistics section of the JLPGA website provided the profiles, career prize money won, and career tournament wins of each of the 369 players. The roster included active as well as retired players who were qualified and admitted as JLPGA members.

\section{Dominance of Elite Players}

Table 1 presents the data on frequency distribution of players by total career tournament wins. The frequency distribution is right-skewed or shows a positive skewness in that a large cluster of players is concentrated in the category of no tournament wins. On the other extreme, Hisako Higuchi recorded 69 wins in her career. Nine players have recorded 25 or more wins in their careers. Five (Hisako Higuchi, 69 wins; Tatsuko Ohshako, 45 wins; Ayako Okamoto, 44 wins; Yuko Moriguchi, 41 wins; and Nayoko Yoshikawa, 29 wins) of those nine players joined the JLPGA before 1980, while one player (Ai-Yu Tu, 58 wins) became a JLPGA player in 1981, one player (Yuri Fudoh, 50 wins) began her JLPGA career in 1997, one player (Mi-Jeong Jeon, 25 wins) started in 2005, and one player's (Sun-Ju Ahn, 28 wins) rookie season was 2010. These nine elite players recorded 389 wins $(27.3 \%)$ out of the total 1423 tournament career wins that were contributed by 369 players during the time span of nearly 52 years, from 1968 to 2019. It is a remarkable sign of the dominance of elite players in the history of the JLPGA that nine $(2.4 \%)$ of the total 369 players shared $27.3 \%$ of the total career tournament wins. It should be noted that Ayako Okamoto won 18 tournaments on the LPGA Tour in addition to her 44 wins on the JLPGA Tour. She played on both the JLPGA and LPGA Tours between 1982 and 1992, and she won 20 tournaments on the

\footnotetext{
${ }^{25}$ Source: www. reuters.com (reuters.com/article/us-golf-japan-women-idUSKBNIEM08P). /Japan Ladies' Tour Thrives with Healthy Sponsorship, Full Schedule. Reuters, December 21, 2017

${ }^{26}$ Source: www.reuters.com

${ }^{27}$ Source:www.reuters.com
} 
JLPGA and had 18 wins on the LPGA during that period. Had Okamoto not split her play between the two tours, she might have recorded more wins in the JLPGA Tour. Yuri Fudoh is another player with an impressive career. She achieved 50 tournament wins on the JLPGA Tour between 1999 and 2011, an average of nearly 4 wins per year. Fudoh's career pattern seems to underline the importance of the density of the winning record in a player's career path. Ai-Yu Tu had 58 wins in her JLPGA Tour career which began in 1981. It is a remarkable accomplishment for an international player to record such a large number of tournament wins, being ranked second only to Higuchi's 69 wins. Tu's success on the JLPGA Tour triggered the influx of international players, especially Taiwanese players, to the JLPGA Tour [28]. ${ }^{28}$

\section{Left-Leaning Curve of Career Wins}

In order to examine overall features in the distribution of players by the number of career wins, the data presented in Table 1 is rearranged. Table 2 shows the percent distribution of the players by grouped category of career tournament wins. One of the most striking findings from the data in Table 2 is that nearly $38 \%$ of the 369 players did not win a single tournament on the JLPGA Tour in their careers. About $19 \%$ of the 369 players listed in the archive of JLPGA had one tournament win in their career. The proportion of players who had five or more wins in their careers was about $23 \%$. The mean number of career wins for the total pool of players was 3.86. The mean increases to 6.22 for the pool of players who recorded one or more career wins. The fact that 140 of the total 369 players had no tournament win in their entire career has significant implications for the professional career development and general well-being of those players.

\section{Players Without a Win in Their Entire Career}

Table 3 shows the background characteristics of the 140 players who failed to win a tournament in their careers on the JLPGA Tour. In terms of the players' playing status, 17 were active at the tour on a full-time basis. Forty-eight players were retired, and 23 players were retired, but played on the senior tour in the 2019 season. Thirty players are in the category of semi-retired in that they played fewer than 10 tournaments of the JLPGA Tour in 2019. Fifteen players played on the second tier tour of the JLPGA, the Stepup Tour, in the 2019 season. Hence, only 17 of the 140 non-winners may still have a legitimate shot at winning an official tournament of the JLPGA Tour. Table 3 also shows the distribution of non-winners by year when the player was admitted as a JLPGA member. As shown in Table 3, nearly 64\% of the non-winners joined the JLPGA Tour prior to 2010, while those players who became JLPGA Tour members since 2010 comprised about $31 \%$. Only nine players of the non-winner group joined the JLPGA Tour since 2015, and thus have played 5 years or less on the tour. The likelihood of winning a tournament of the tour in the future by those players who

\footnotetext{
${ }^{28}$ On the basis of the career total victories of the elite players who dominated the tour during different periods, it may be possible to designate the eras of JLPGA Tour although there may be an overlap between the eras: Higuchi era, 1968-1985; Okamoto era, 1975-1990; Tu era, 1985-1997; Fudoh era, 1997-2011. In the case of the eras of PGA Tour, previous study reported that "the best players in each era are comparable, but the median and below-average players are getting much better over time" [28].
} 
Table 1 Frequency distribution of JLPGA players by career total number of tournament wins

\begin{tabular}{|c|c|c|c|c|c|c|c|}
\hline $\begin{array}{l}\text { Number of } \\
\text { wins }\end{array}$ & $\begin{array}{l}\text { Number of } \\
\text { players }\end{array}$ & $\begin{array}{l}\text { Number of } \\
\text { wins }\end{array}$ & $\begin{array}{l}\text { Number of } \\
\text { players }\end{array}$ & $\begin{array}{l}\text { Number of } \\
\text { wins }\end{array}$ & $\begin{array}{l}\text { Number of } \\
\text { players }\end{array}$ & $\begin{array}{l}\text { Number of } \\
\text { wins }\end{array}$ & $\begin{array}{l}\text { Number of } \\
\text { players }\end{array}$ \\
\hline 0 & 140 & 15 & 1 & 30 & 0 & 45 & 1 \\
\hline 1 & 70 & 16 & 2 & 31 & 0 & 46 & 0 \\
\hline 2 & 35 & 17 & 2 & 32 & 0 & 47 & 0 \\
\hline 3 & 21 & 18 & 4 & 33 & 0 & 48 & 0 \\
\hline 4 & 19 & 19 & 0 & 34 & 0 & 49 & 0 \\
\hline 5 & 15 & 20 & 1 & 35 & 0 & 50 & 1 \\
\hline 6 & 10 & 21 & 1 & 36 & 0 & $51-57$ & 0 \\
\hline 7 & 11 & 22 & 1 & 37 & 0 & 58 & 1 \\
\hline 8 & 7 & 23 & 3 & 38 & 0 & $59-68$ & 0 \\
\hline 9 & 3 & 24 & 1 & 39 & 0 & 69 & 1 \\
\hline 10 & 6 & 25 & 1 & 40 & 0 & & \\
\hline 11 & 1 & 26 & 0 & 41 & 1 & & \\
\hline 12 & 1 & 27 & 0 & 42 & 0 & & \\
\hline 13 & 2 & 28 & 1 & 43 & 0 & Total & Total \\
\hline 14 & 3 & 29 & 1 & 44 & 1 & 1423 & 369 \\
\hline
\end{tabular}

Source: lpga.or.jp

failed to win a tournament after competing 10 years or longer on the tour appears to be extremely low. Without winning a tournament in the preceding year, one would have to be ranked 50th or better on the previous year's season-ending money list in order to qualify to play in the following year on the JLPGA Tour.

A player may display consistent performance throughout an entire season and earn enough prize money to qualify on the basis of the money list without winning a tournament. It is very difficult, however, to make the priority list on the basis of the money list ranking without winning a tournament. The structure of the payout and distribution of the tournament purse is constructed by allocating $15 \%$ to the winner,

Table 2 Percent distribution of JLPGA players by career total tournament wins

\begin{tabular}{llr}
\hline Number of career wins & Number of players & Percent \\
\hline 0 & 140 & 37.94 \\
1 & 70 & 18.97 \\
$2-4$ & 75 & 20.32 \\
$5-9$ & 46 & 12.47 \\
$10-14$ & 13 & 3.52 \\
$15-19$ & 9 & 2.43 \\
$20-29$ & 10 & 2.71 \\
$30+$ & 6 & 1.63 \\
Total & 369 & 100.00 \\
\hline
\end{tabular}

Source: lpga.or.jp 


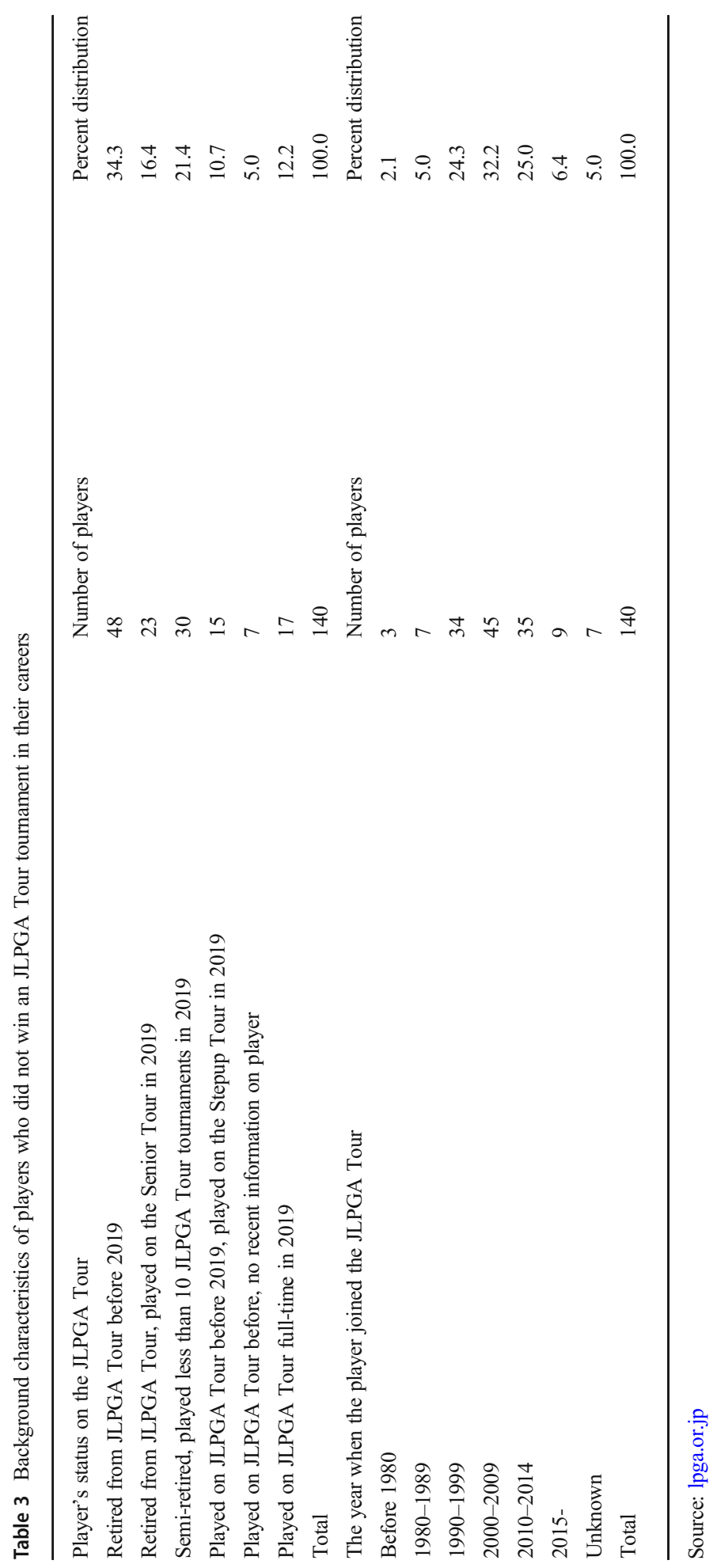


$9.3 \%$ for the 2 nd place, $6.75 \%$ for the 3 rd place, $2.06 \%$ for the 10 th place, and so on. Hence, a player must finish in the 10th place in more than eight tournaments in a season to earn the prize money that would be equivalent to one tournament win.

In any case, winning a tournament tends to bring recognition and status in the community of players on the tour. One would also expect winning to enhance a player's confidence level in her playing. More importantly, it would be extremely difficult to qualify to play on the tour continuously without winning an official event on the tour. In this context, winning appears to be the only way to survive on the tour. Many players in the group of non-winners played on the JLPGA Tour but were relegated to the Stepup Tour because they failed to qualify to play on the tour in the following season for not making the top 50 on the money list at the end of the preceding season. They would have to take the Qualifying Tournament (QT) route to return to the JLPGA Tour. The QT of the JLPGA is equivalent to the Q-Series of the LPGA.

The QT includes two stages, namely the first and final stages. The first stage is held at three different regional sites, and those who pass the first stage participate in the Final QT, which is scheduled around the first week of December each year. In the Final QT for the 2020 season, 297 players competed and 96 passed. Only the top group of 96 qualifiers are assured to play on the JLPGA Tour regularly; the remaining group get assigned to the Stepup Tour. The JLPGA Tour includes the top 50 players on the previous year's season-ending money list. ${ }^{29}$

Considering the demanding criteria that are required to stay qualified to play on the JLPGA Tour, the career non-winners who are still around the JLPGA may be the truly resilient survivors of the tour. The presence of a large group of players who failed to win an official tournament of the JLPGA Tour in their entire careers manifests the fluidity of the players' status in their professional career life cycles. As discussed in the previous section, the degree of uncertainty and the possibility of downward mobility of the players from one season to the next are integral parts of the professional athlete's career. The structure of recruitment, retention, and attrition of the players may be what helps professional sports sustain the extremely high level of performance of players and the support of fans.

\section{Winning a Tournament in the First Season of the Tour}

There is an old saying, "Well begun is half done." Such an observation may be relevant to the career development of professional athletes. Winning an official PGA or LPGA event as a rookie would be a rare accomplishment. The data in Table 4 show that only eight of the 38 players who had 10 or more career wins on the JLPGA Tour recorded one or more tournament wins on the tour in their rookie season: Hisako Higuchi in 1968, Ai-Yu Tu in 1981, Yueh Chyn-Huang in 1984, Bie-Shyun Huang in 1985, Ai Miyazato in 2004, Jiyai Shin in 2008, Sun-Ju Ahn in 2010, and Misuzu Narita in 2012. Ai Miyazato won one JLPGA tournament as an amateur in 2003, and she had 5 victories on the JLPGA Tour in 2004. Ahn also won 4 tournaments in 2010 which was her first season on JLPGA. From the

\footnotetext{
${ }^{29}$ For a comparison, on the LPGA Tour of the US top 80 and ties on the money list at the end of a season would have an exempted status for the immediately following season. ("20201pgapriority-listfinalocs082420.pdf," lpga.com)
} 
Table 4 JLPGA players who won the JLPGA Tour tournament in their rookie year

\begin{tabular}{lll}
\hline Player's name of and country of origin & Player's rookie year & $\begin{array}{l}\text { Number of JLPGA wins } \\
\text { in a player's rookie year }\end{array}$ \\
\hline Hisako Higuchi (Japan) & 1968 & 1 \\
Ai-Yu Tu (Taiwan) & 1981 & 1 \\
Yueh-Chyn Huang (Taiwan) & 1984 & 1 \\
Bie-Shyun Huang (Taiwan) & 1985 & 1 \\
Ai Miyazato (Japan) & 2004 & 5 \\
Jiyai Shin (Korea) & 2008 & 1 \\
Sun-Ju Ahn (Korea) & 2010 & 4 \\
Miszu Narita (Japan) & 2012 & 1 \\
\hline
\end{tabular}

Source: lpga.or.jp

perspective of the athlete's career life cycle model, winning a tournament as a rookie puts the player in a head-start position in the initiation stage.

Five of the eight players who had a tournament victory in their rookie season were internationals: Ai-YuTu, Bie-Shyun Huang, and Yueh-Chyn Huang are from Taiwan, while Ahn and Shin are from Korea. These foreign-born players were not rookies on the JLPGA Tour in a strict sense. Each of them had an extensive experience as a professional tour player in their respective country prior to becoming a regular member of the JLPGA Tour. Ai-Yu Tu had 11 tournament victories before joining the JLPGA. Her 11 wins were in Taiwan or from the events of minor tours in Japan. Tu won her first official event of the JLPGA Tour at age 27.

Sun-Ju Ahn played on the Korean (KLPGA) tour for four seasons, 2006-2009, and she had 7 tournament wins during that period. Although she qualified to play on the LPGA tour by passing the LPGA Q-School in 2009, she decided to play on the JLPGA Tour instead. Ahn was 22 years old when she joined the JLPGA as a regular member of the tour in 2010, and she had four tournament victories in her first season on the JLPGA tour. She won the JLPGA Tour money title four times up to that point, in 2010, 2011, 2014, and 2018. Ahn became the second foreign-born player to win the JLPGA's money title in 2010. Ai-Yu Tu was the first foreign-born player to win the title in 1991.

Jiyai Shin has had a truly outstanding record of accomplishments over the past 15 years. She won the rookie of the year title on the KLPGA Tour in 2006 and compiled 21 tournament victories on the KLPGA Tour. She was also the player of the year as well as the money leader of the KLPGA in both 2007 and 2008. Shin recorded 11 career victories on the LPGA Tour between 2008 and 2013, including two majors, Ricoh Women's British Open in 2008 and 2013. Excluding the two Women's British Open and one Evian Masters, she won three additional tournaments on the Ladies European Tour. She was ranked number one in the Rolex World Women's Golf Ranking in 2010. Shin had 22 career victories on the JLPGA Tour thus far, and she was the JLPGA's Player of the Year in 2018.

Ai Miyazato may have been one of the most popular golfers, including both men and women golfers, in the history of golf in Japan. As an 18-year-old amateur, she won a JLPGA tournament in 2003. Miyazato had five victories on the JLPGA Tour in 2004 
as a rookie of the tour. After winning 14 tournaments on the JLPGA, she moved on to the LPGA in 2006. In fact, she won the LPGA Qualifying Tournament in December 2005 , and the margin of her victory was 12 strokes. Miyazato had nine career victories on the LPGA Tour, and she was ranked number one in the World Women's Golf Ranking in the part of the 2010 season when she won five LPGA tournaments. Although her accomplishments on the LPGA Tour are definitely impressive, her Japanese fans might have expected more from her in light of her success on the JLPGA Tour and her performance at the LPGA Qualifying Tournament. Some pundits speculated that high expectations of her fans in Japan put her under intense pressure to win on the LPGA tour and that she struggled to adjust to playing LPGA tour courses. ${ }^{30}$ Nevertheless, Miyazato's popularity in Japan has remained solid as evidenced by the fact that the JLPGA named one tournament after her, the "Miyazato Suntory Ladies Open," following her retirement from playing on the tour in 2017.

\section{Time Span Between Admission to the Tour and First Career Win}

As indicated earlier, the athlete's career life cycle model stipulates that an athlete transitions from the initiation stage to the development stage and then to the mastery, maintenance, and discontinuation stages. The duration of each stage varies by individual player. The length of time a player takes in the initiation stage has significant implications for the player's progress in her career. From the data in Table 4, it is possible to determine the number of years spent by a player between becoming a regular tour member and her first career win.

As discussed above, eight of the 38 elite players had their first career victory as a rookie. Eight players had their career first win by the end of their second season on the tour, another eight players by their third year, and six players by their fourth year on the tour. Hence, 30 of the 38 elite players recorded their first career victory within 4 years on the tour. One player's first win came in her 9th year on the tour. For the group of six players who had 30 or more career wins, the mean time span for the first victory was 1.5 years, while the mean time span for the group who had 10 career wins was 4.3 years. Other than these two extreme groups, however, there was no clear pattern of relationship between the total number of career wins and the length of time spent before the career first win.

\section{Time Span Between First and Last Career Win}

An athlete's career durability is one of the most important dimensions of his or her productivity. ${ }^{31}$ Previous studies have reported that the playing careers of professional athletes are fairly short, especially for players in team sports leagues such as the NFL, NBA, MLB, and NHL. The playing lives of noncontact individual sports such as golf and tennis may be much longer than those of contact sports players. The career durability of players may be measured by the duration of time in which the player maintains an active player status and competes as a player in his or her respective sport. One possible problem of such an inclusive measure is that many players in the late

\footnotetext{
${ }^{30}$ Source: https://www.golfchannel.com/article/golf-central-blog/two-time-champ-miyazato-end-career-evian

${ }^{31}$ The concept of career durability is used here as a proxy measure of a player's career success.
} 
stages of their professional career may have the active player status in theory only, but realistically the player may be semi-retired and playing in a limited number of events. In this study, the time span between the first and last career victory on the JLPGA Tour was used to measure the durability of a player's productive career. It should be acknowledged that this measure is quite a restrictive indicator of a player's career durability. However, in light of the ambiguity of player's status in the late stage of his or her career, the time span between the first and last tournament victory may indicate the pragmatic length of the player's career durability. Table 5 shows the length of time between the first and last tournament victory of the 38 players who recorded 10 career wins or more on the JLPGA Tour. Ten of the 38 players are still active on a full-time basis as of the 2019 season of the tour. Thus, those 10 cases were excluded from the analysis of career durability.

As shown in Table 5, the time span between the first and last tour victory of the 28 players ranged widely from Fukumi Tani's 4 seasons to Ayako Okamoto's 25 seasons. Fukushima Tani had 11 wins on the tour between 1987 and 1990, but she did not have any more wins after the 1990 season. On the other extreme, the World Golf Hall of Famer Ayako Okamoto had her first tour win in 1975 and her last tour victory in 1999 on the JLPGA Tour. She had multiple tournament victories in 10 of the 25 seasons between her first and last tournament wins on the JLPGA Tour. In fact, Okamoto won 8 tournaments on the JLPGA Tour in the 1981 season. She played on the LPGA Tour between 1982 and 1992 on a full-time basis and recorded 17 victories on that tour.

The time span between the first and last tour victory was compared for different entry cohorts in terms of the year when they became a member of the JLPGA Tour. The mean time span for the pre-1980 cohort was 18.3 years, while the mean time span was 13.5 and 10.5 years for the 1980-1989 and 1990-1999 cohorts, respectively. This finding may suggest that the productive career durability of the earlier entry cohort was longer than that of the recent cohorts. Another possibility is that the tour has become increasingly more competitive in that the rising level of competition on the tour has had a negative impact on the career durability of the tour players. One possible cause for a rise in the competition level on the tour may be the increasing influx of international players into the JLPGA Tour. Only two international players were first-time winners in Japan before 1980, while the number increased to 16 for the period between 1980 and $1989 .^{32}$ In addition, since the LPGA Tour expanded the number of tournaments in its Asian swing to China, Taiwan, and Korea in addition to Japan, the number of the LPGA Tour players competing in the JLPGA Tour tournaments including the TOTO Japan Classic has increased in recent years. ${ }^{33}$

\section{Peaks and Dips in Tournament Wins}

The shape of an athlete's career life cycle curve may be quite different from the prototype of the life cycle stage model curves considering the particular characteristics of the athlete's career as discussed in the previous section. The breadth and height of the player's career life cycle stages are important dimensions that may define the

\footnotetext{
32 Source: https://www.lpga.or.jp/stats/first-victory

${ }^{33}$ Source: https://www.lpga.com/news/2019/2019-lpga-tradition-continues-with-44th-toto-japan-classic. The TOTO Japan Classic is co-sponsored by JLPGA and LPGA Tour.
} 


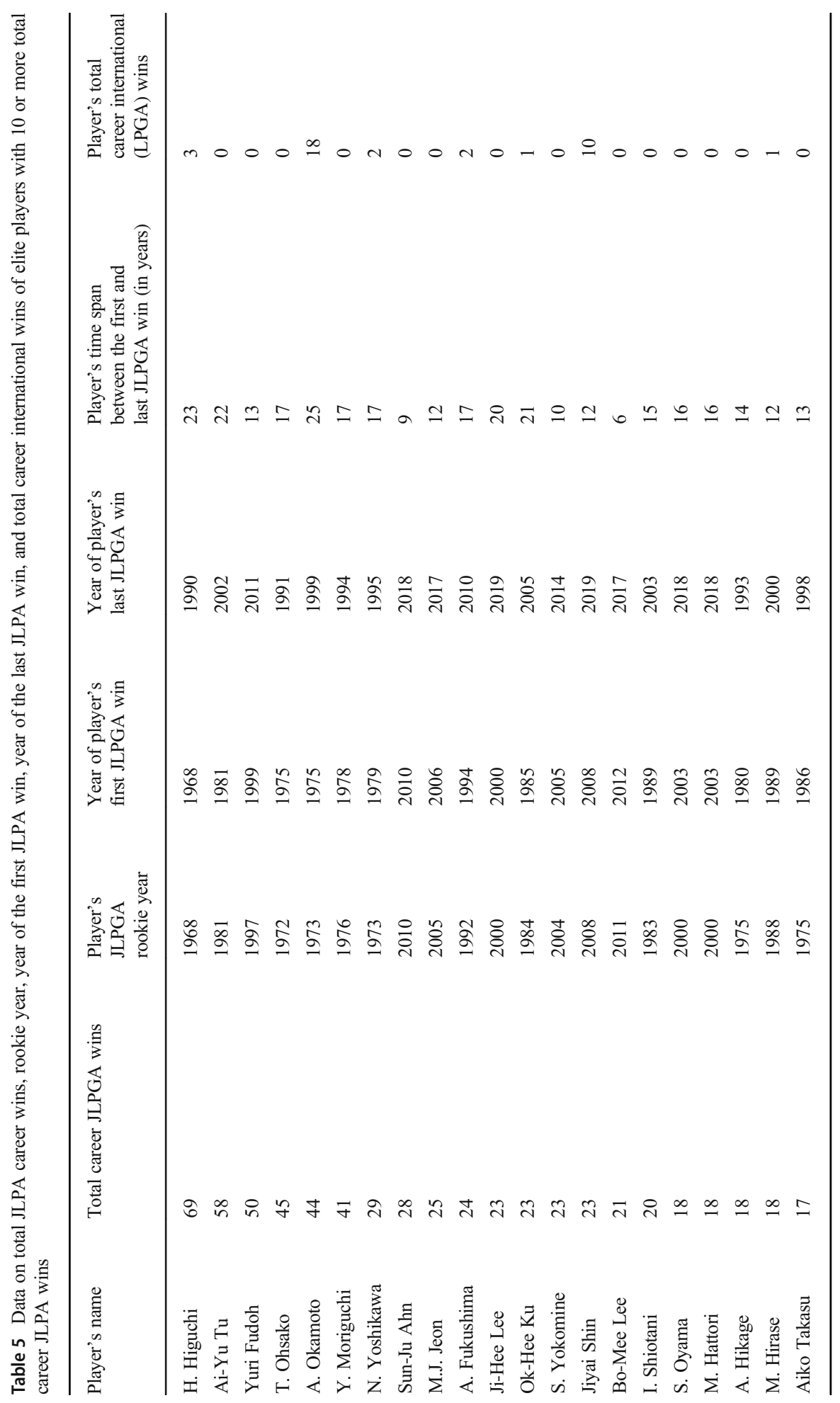




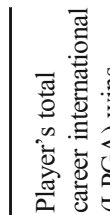

$00000-a 0000000$ in 00

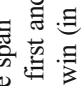

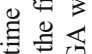

क

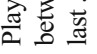

$M$ o n $M=M 0=0 \infty+\vec{N} \cong= \pm n n$

के

胥吕

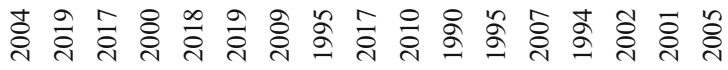

它 $\frac{1}{3}$

害过

离蒡

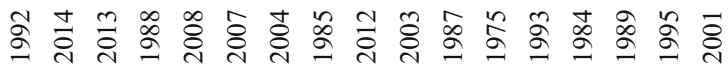

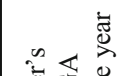

离芯兽

ळ

$\stackrel{2}{1}$

峁

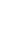

플

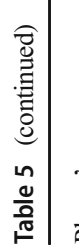

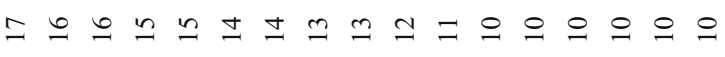

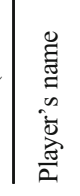

刑 Springer 
success and failure of the player's career. In this section, the distribution of career victories by the life cycle stages of each player is analyzed. The analysis will reveal whether each of the selected players had an early-peak, broad-peak, or late-peak career life cycle. The total career length of each of the selected players was divided into 5-year segments. The number of tournament wins by the player for each of the 5-year periods was counted. Then, the number of tournament wins for each of the 5-year periods was compared to determine during which period the player produced the largest number of wins. The largest number of victories by each player is marked in italics in Table 6 .

Table 6 shows that 19 of the 38 selected players had the largest number of tournament wins during their second 5-year period ("broad-peak"), while 11 players won more tournaments during their first 5-year period ("early-peak"). The number of tournament wins during the third 5-year period was the largest for 6 players ("latepeak"), and for two players, the fourth 5-year period showed more wins than any other periods ("late-late-peak"). To check whether any particular category of peak has an advantage in the number of career victories, the mean and median of each category were compared. Both the mean and median of the broad-peak category were slightly greater than those of the early and late peak categories. The mean number of tournament wins of the broad-peak category (22.4) was larger than that of the early-peak category (20.1). The comparison showed that the players in the early-peak category did not have any advantage in terms of career wins over the broad-peak and late-peak categories. There may be a compensatory effect in a player's pace of tour wins. That is, a fast paced success in the early stage of a player's career may be followed by a slowdown in the subsequent stages in the player's career life cycle.

Ten of the 38 elite players who had 10 or more victories on the JLPGA Tour were foreign-born players, four Taiwanese and six Korean. Six of the foreign-born players were in the early-peak category, three were in the broad-peak, and one was in the latepeak category. The concentration of the international players in the early-peak category was expected. As indicated earlier, these international players had substantial playing experience on the professional tour in their home country before joining the JLPGA Tour. They won numerous tournaments on the tour in their country. From the perspective of the career life cycle model, the international players entered the initiation stage after having a valuable professional experience in the preparation stage of their careers. On the other hand, most of the native-born Japanese players did not have any professional tour experience before joining the JLPGA Tour, and thus, they may have to adapt to the rigors of the tour after joining the JLPGA Tour. That may be the primary reason why the native-born players had more victories in the second 5-year period than in the first 5-year period. For them, the first 5-year period was partially the preparation stage although they were already in the initiation/introduction stage.

\section{The Official Money Titles and a Player's Career Stage}

In the previous sections, the players' wins in official tournaments at different stages of the players' life cycle were examined. Their career record of tournament wins may be one of the most reliable indicators of their performance on the tour. However, counting only the number of tournament wins would not be sufficiently inclusive to take into account the players' career pathways in their entirety. Some professional sport tours use the total amount of prize money won by a player as a yardstick of the player's 
78

East Asia (2021) 38:61-91

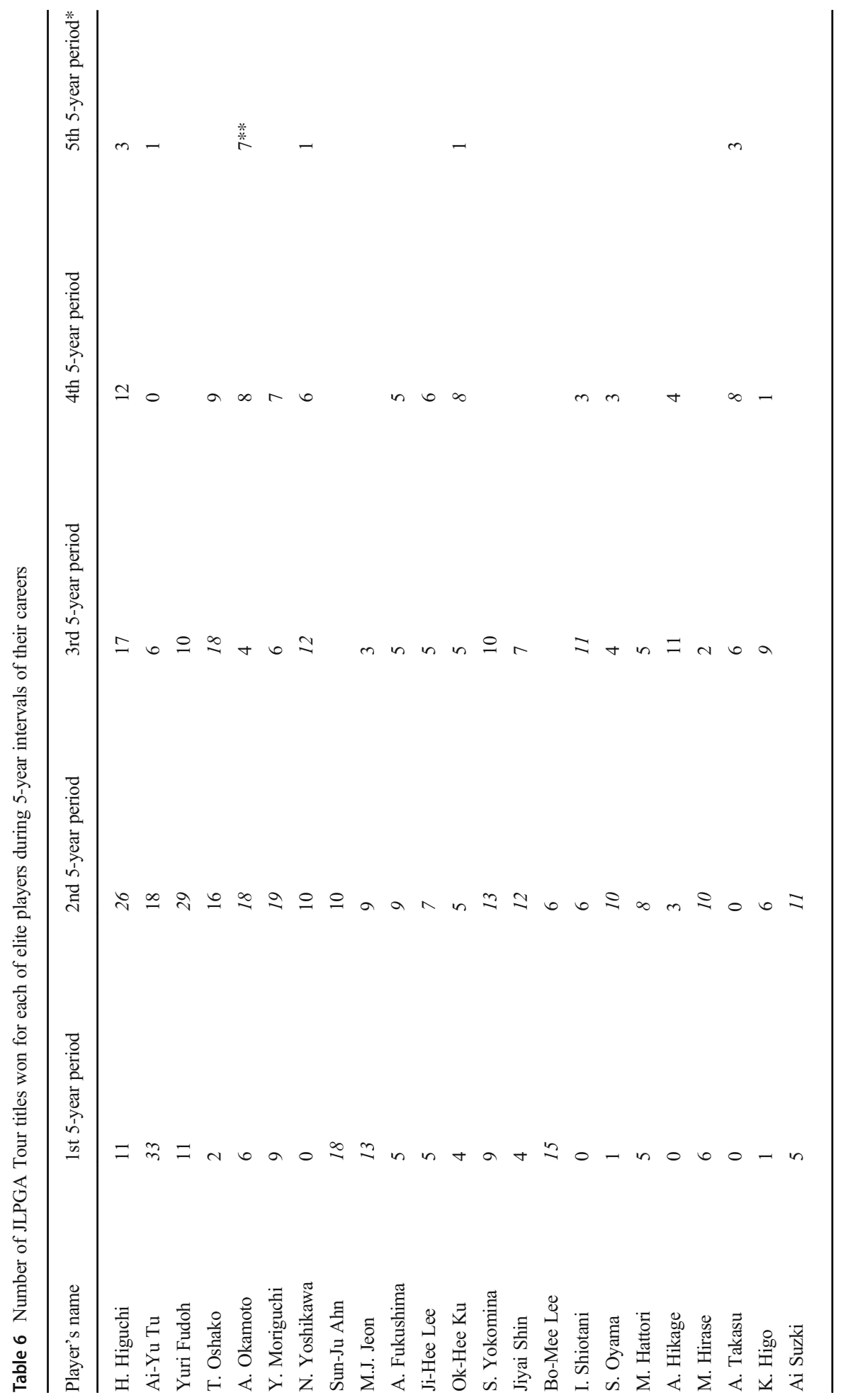

를 Springer 


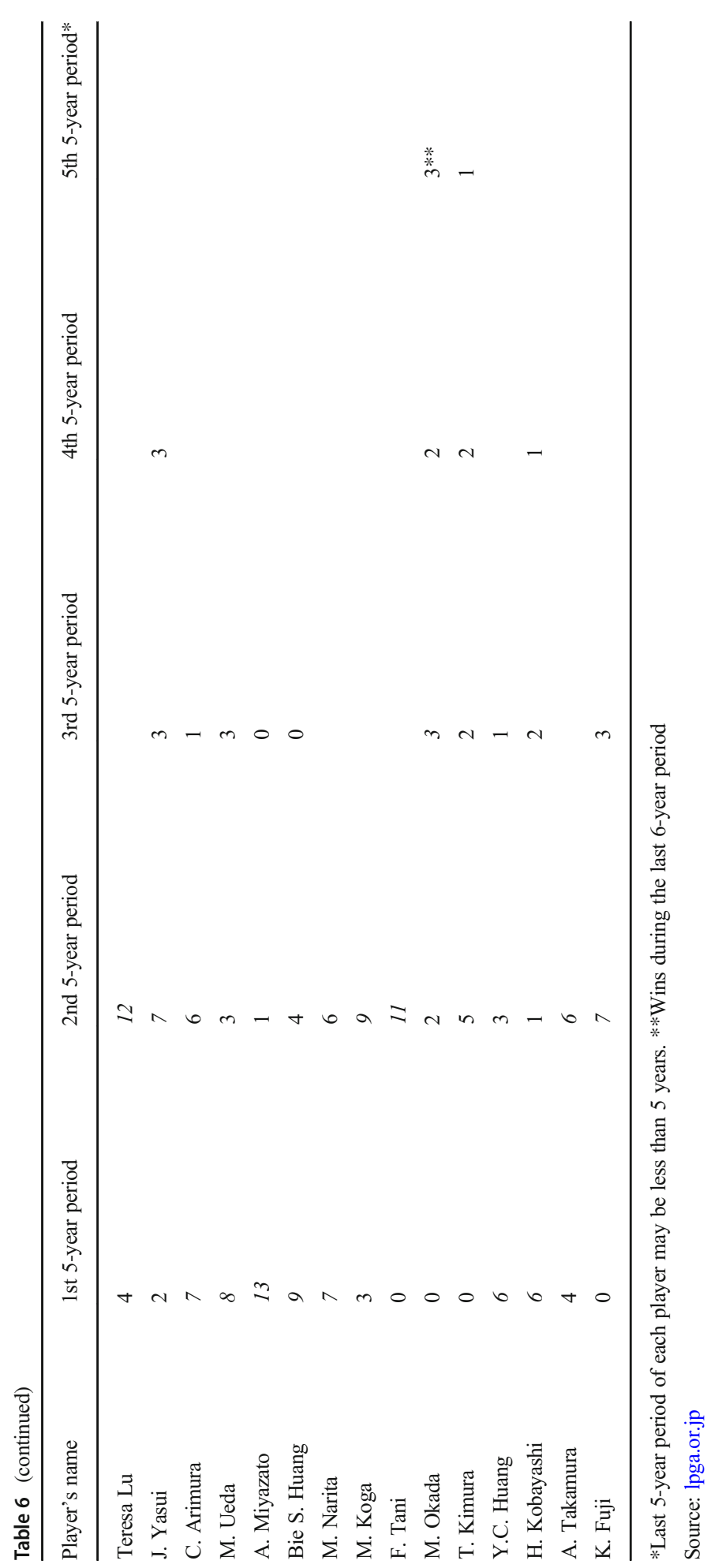


performance. The "money ranking" is likely to reflect the "score card" in each and every event where the player competed. Hence, the analysis of the money ranking data may complement the investigations of the data on the tournament wins. ${ }^{34}$

Both the PGA and LPGA have a long history of using a player's ranking in the previous year's season ending money list to determine the priority list for the following season. The ranking in the career money list is also considered in the priority list. In the case of the LPGA Tour, the top 80 and ties on the previous year's season-ending money list would be on the priority list for the current season. In addition, players in the top 20 on the career money list as of the last official tournament of the previous year would be on the priority list of the following tour season. For the JLPGA Tour, the top 50 on the previous year's money list qualify to play on the tour in the following year's season. Unlike the policies of the LPGA Tour, the JLPGA Tour does not offer a seeding on the qualifier list for the members in the top 20 on the career money list. Becoming the winner of the official money title of a tour season is considered to be a major accomplishment of the players on the professional golf tours. To win the money title, a player must demonstrate outstanding performance in all tournaments consistently in which the player may compete throughout the entire season. The research question addressed in this section is at what stage of the career life cycle a player may win the official money title of the season. Another issue is whether or not the career point when a player wins the money title fits to the career life cycle stage prescribed in the theoretical model of athletes' career life cycles.

Table 7 presents the information on the number and career point on the tour of the players who won the official money title in their careers between 1967 and 2019. Of the possible 53 money titles for the period, 19 players listed in Table 7 had won 51 times. Three players, Higuchi (12), Tu (7), and Fudoh (6), together contributed 25 of 51 money titles. These top three players in terms of the number of money titles are also the top three in career wins of JLPGA tournaments. There were several players who had more than 25 tournament victories in their careers on the tour, but they failed to win even a single money title. Having numerous tournament victories in a player's career does not necessarily induce the money title. To win the money title of a season, a player may have to secure multiple tournament victories in that season. Thus, it is not the total number of career wins but the concentration of the wins in certain seasons that would lead to the money titles.

As shown in Table 7, nearly two-thirds of the total number of official money titles on the JLPGA Tour over the last 53 years were secured by the players who were in their 7 th or earlier seasons on the tour at the time they won the money title. Three players won their money title in their 8th season, while five players captured the money title on their 9 th season on the tour. Twelve money titles were captured by players who were on the tour for four or fewer seasons. In light of the fact that consistency and durability of performance by a player over an entire season are required to win the money title, the concentration of money titles by players in relatively early stages of their career life cycle is extremely intriguing. Players who won the money title at the early stages of their careers may have started the tour with superb talent and

\footnotetext{
34 The data on "top 10 finishes" of players in their careers were considered. However, the patterns of variations in top 10 finishes were quite similar to those of tournament wins. The money rankings provided a greater range of variations in each player's career than that for both the tournament wins and top 10 finishes.
} 
Table 7 The number of the official money titles won by players and career stage when the players won the titles

\begin{tabular}{llll}
\hline Player's name & $\begin{array}{l}\text { Number of } \\
\text { official money titles won }\end{array}$ & Career stage at winning the money title & $\begin{array}{l}\text { Total number } \\
\text { of years on the tour }\end{array}$ \\
\hline H. Higuchi & 12 & 1st-10th, 12th, 13th seasons & 23 \\
Ai-Yu Tu & 7 & 2nd-6th, 9th, 11th & 22 \\
Y. Fudoh & 6 & 4th-9th & 19 \\
S. Ahn & 4 & 1st, 2nd, 5th, 9th & 10 \\
T. Ohsako & 3 & 6th, 9th, 16th & 17 \\
A. Fukushima & 2 & 5 th, 6th & 20 \\
M. Hirase & 2 & 6th, 7th & 15 \\
B. Lee & 2 & 5th, 6th & 9 \\
I. Shiotani & 2 & 10 th, 13th & 19 \\
A. Suzuki & 2 & 5 th, 7th & 7 \\
M. Hattori & 1 & 8th & 23 \\
M. Jeon & 1 & 7 th & 15 \\
A. Okamoto & 1 & 7 th & 27 \\
S. Oyama & 1 & 7 th & 20 \\
M. Ueda & 1 & 3rd & 15 \\
S. Yokomine & 1 & 5 th & 16 \\
Total & 48 & & \\
\hline
\end{tabular}

Source: lpga.or.jp

preparation. Hence, these players may skip the usual initiation stage of the career life cycle and move right into the growth or even maturity stages. Although highly talented young super stars emerge in many professional fields, the likelihood of such cases in sports, especially in individual sports, may be much higher.

On the other hand, there were two players, T. Ohsako and N. Yoshikawa, who won the money title in the 16th season of their careers, the latest career point winners among the 19 players on the list of money title holders. Ohsako had an amazing streak of money ranking in that she was ranked in top five for 14 consecutive years between 1975 and 1988. During that long streak, she won three money titles, with her first win in her 6th season, second win in her 9th season, and third win in her 16th season. Yoshikawa also showed an impressive record in the official money ranking: ranked in the top 1016 times during the 23-year period between 1973 and 1995. Both players had a long run of consistency and durability in their performance on the tour. Their career curves seem to fit a broad-peak shape quite nicely. On the whole, the 19 money title winners manifested variant career curves in terms of the stage at which they captured the official money titles: "early-peak," "broad-peak," and "late-peak," and "late-late-peak."

\section{The Players' Career Life Cycle Stages Based on the Annual Official Money Rankings}

Each player's yearly official money ranking data over her entire career may reveal the breadth and height of each of the career life cycle stages. The 38 elite players who are 
included in the analysis are those who had 10 or more official tournament victories in their careers on the JLPGA Tour. Twenty-seven of the 38 players were retired, while 11 players were active on the tour as of the 2019 season.

Figure 1 presents the players' rankings on the official money list by their career point on the JLPGA Tour. The players' career points range from the 1 st year to the 35 th year on the tour, while the lowest ranking on the money list was 188th. The trend line in Fig. 1 indicates that there was a fairly steep decline in the official money ranking as the players went through the career stages from an early to a late stage of their career life cycles. As shown in Fig. 1, money rankings of the players varied substantially at a given point of the players' careers on the tour. The range of variation in the money rankings in the rookie season of the players was substantial. The extent of variation tended to decline afterwards and the players were clustered around the 50th or better in the money rankings between the 3rd and 9th seasons on the tour. By around the 18th season of the players' tour career, one-half of the players reaching that stage would be split into two groups, below the 50th and above the 50th. There were only a limited number of players who were still ranked in the top 50 in the money ranking beyond the 22nd season. As indicated earlier, one of the primary criteria of qualifying for the priority list for the next year's season on the JPLGA Tour is being in the top 50 on the official money list at the end of the previous year's season. Only a handful of players who do not make the priority list may be able to play on the tournament sponsor's invitation. The profiles of the players reveal that most of the players in the late stage of their career cycle play two or three tournaments on the JLPGA Tour for their last several seasons before a complete retirement.

The JLPGA Tour offers a lifetime exemption to those member players who secure 30 or more tournament victories over their tour careers. As of the end of the 2019 season, six players were qualified to play on the tour for the 2020 season on the basis of that criteria. They were Hisako Higuchi, Ai-Yu Tu, Yuri Fudoh, Tatsuko Ohsako, Ayako Okamoto, and Yuko Moriguchi. Some players who are retired from the JLPGA Tour may continue to compete in the senior tour, the Legends Tour. On the whole, it is difficult to delineate a player's career life cycle stage when the "discontinuation stage of competitive sports" starts. ${ }^{35}$ One important finding from the analysis of the data on the individual player's yearly official money ranking for the entire tour career is that the 38 elite players did not experience any noticeable interruptions in their entire careers. The money ranking information for six players was missing for one season, and the information of one player for three seasons, not three consecutive seasons, was not available without any explanations. All seven cases of the missing data were for a relatively late stage of their careers. The JLPGA Tour stipulates the return from maternity leave as well as medical leave in the criteria for determining the qualification for the priority status of the players. Only one player received an exemption on the

\footnotetext{
35 Ten of the 38 selected elite players were foreign-born, and they tended to manifest background characteristics quite different from those of the Japanese players on the JLPGA Tour. For example, the foreign-born players showed more tournament wins in the early stage of their career life cycle than the Japanese-born players. It is useful to compare the patterns of career life cycles between the two groups of players. The range of variation in money rankings at a specific career life cycle point on the tour seems to be slightly less for the group of foreign-born players than that for the Japanese players. The foreign-born players tended to be more clustered at the upper portion of the money ranking scale than the Japanese players were. The overall pattern of decline in money ranking from early to late stage of a player's career life cycle turned out to be quite similar.
} 


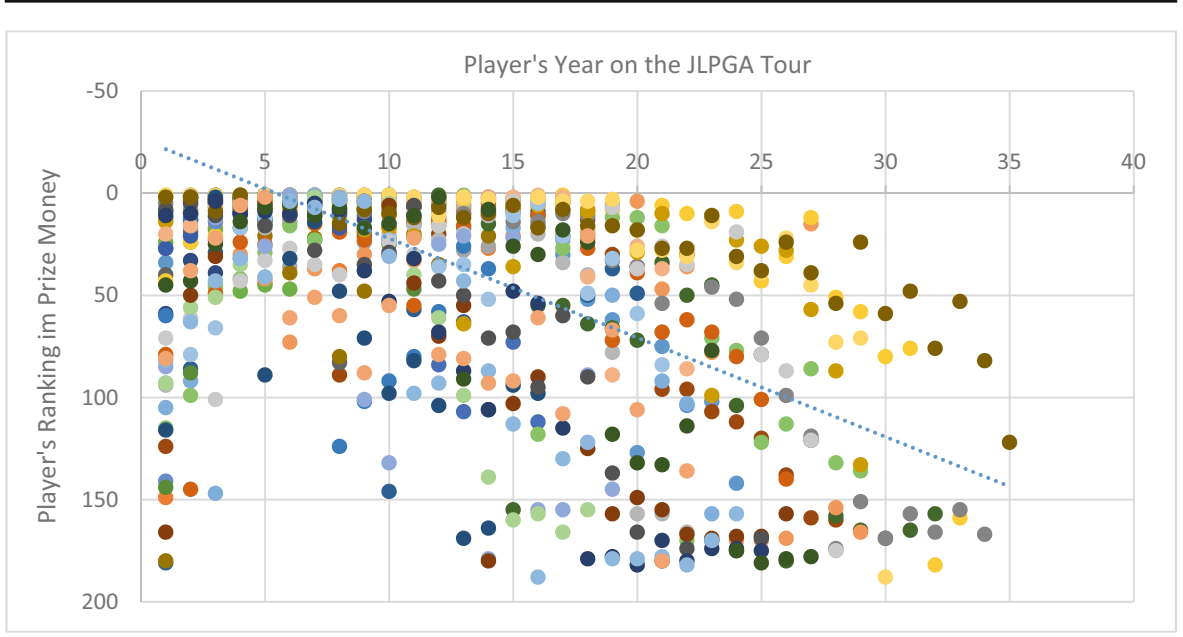

Fig. 1 Player's ranking in prize money by career stage. Source: lpga.or.jp

basis of the maternity leave for the 2020 season of the JLPGA Tour. The mean age at first marriage for both men and women in Japan is fairly late: 31.1 for men and 29.4 for women as of 2018. It is expected that the players on the JLPGA Tour are very likely to delay their marriage until close to their retirement.

\section{A Cohort Analysis of Tournament Wins, Money Rankings, and Career Life Cycles}

In the previous sections, the investigation of a player's tournament victories, money ranking titles, and career life cycles was based on the data for the entire pool of the 38 selected players. Such an approach was essential to ascertain the overall structure of the player group's career life cycle stages as indicated by the players' career record of performance on the tour. It was possible to examine the variations in the "height" and "breadth" of the career life cycle stages of the selected player group as a whole. The player group consisted of individual players with a substantial variation in terms of the year when the player started the tour, any year between 1967 and 2013. Each of the JLPGA entry cohorts might have been exposed to quite different conditions of the tour in terms of the structure of the qualifying tournament, number of official tournaments, total amount of the purse for the season, tournament sites, rules of play, guidelines on equipment, competition level of the tour, opportunities for product endorsement contract and corporate sponsorship, availability of transportation to and from the tournament sites, and other factors. More importantly, any changes in the state of the JLPGA Tour with regard to its financial strength, size of fan base, and television coverage of the tournaments would have a different level of impact on the welfare for the different cohorts of the players depending upon the timing of such changes. Hence, it is important to apply the method of cohort analysis to the investigation of career life cycles of the players on the JLPGA Tour.

The 38 selected players were categorized into five cohorts on the basis of the year of the player's entry to the JLPGA Tour: cohort of 1967-1969, cohort of 1972-1976, cohort of 1981-1988, cohort of 1992-1997, cohort of 2000-2008, and cohort of 2010 2013. The cohort size varied from two of the 1967-1969 cohort to 10 of the 1981-1988 
cohort. Table 8 shows that the mean numbers of tournament victories for the two early cohorts, 1967-1969 and 1972-1976, were 39.5 and 32.3, respectively, while the mean number of tournament wins for the 1992-1996 cohort was 21.5. The mean number of tournament victories for the three other cohorts was between 18 and 19. Four of the eight pre-1980 entry cohort players had 41 or more tournament victories in their careers. That raised the mean number of victories for the cohort. On the other hand, tournament wins were more spread among the cohort members for the more recent cohorts than the earlier cohort.

As shown in Table 8, with regard to official money titles by cohort, Higuchi's 11 official money titles put the 1967-1969 cohort having the largest number of the titles, while Tu's 7 titles and Fudoh's 6 titles shared a large segment of their cohort's total of official money titles. Table 8 shows that there was a dominant player for each of the cohorts in terms of both the total number of career tournament victories and the number of official money titles: Higuchi for the 1967-1969 cohort, Ohsako for the 1972-1976 cohort, Tu for the 1982-1988 cohort, Fudoh for the 1991-1997 cohort, and Ahn for the 2010-2013 cohort. Being a member of the same cohort and playing against such a dominant player may have a significant implication for the cohort members' careers.

Figure 2 presents the individual players' money ranking at a specific career point on the tour of the players for the JLPGA entry cohort of 1972-1976, while Fig. 3, Fig. 4, Fig. 5, and Fig. 6 are for the 1981-1988, 1991-1997, 2000-2008, and 2010-2013 cohorts, respectively. A comparison of the figures for different cohorts reveals several important aspects of the player's career life cycles. First, the official money rankings of the players in each cohort are more compacted in the stages between the rookie year and around the 15th season on the tour. Second, the money ranking drops quite consistently after the 15 th season. Third, at a given player's career point on the tour, younger cohorts tend to show less variations in the money ranking than the older cohorts. This may be partially due to the fact that those players in the younger cohort group are truly elite players who started their tour career since 2000 but already secured

Table 8 Mean number of career tournament wins and mean number of money titles won by JLPGA entry cohort

\begin{tabular}{lllll}
\hline $\begin{array}{l}\text { Cohort: year } \\
\text { of entry to JLPGA }\end{array}$ & $\begin{array}{l}\text { Number of } \\
\text { selected players }\end{array}$ & $\begin{array}{l}\text { Mean number } \\
\text { of career wins } \\
\text { on the JLPGA Tour }\end{array}$ & $\begin{array}{l}\text { Total number } \\
\text { of money titles } \\
\text { won by cohort }\end{array}$ & $\begin{array}{l}\text { Cohort's } \\
\text { leading player, wins**, } \\
\text { and titles*** }\end{array}$ \\
\hline $1967-1969$ & 2 & 39.5 & 13 & Higuchi, 69 wins, 12 titles \\
$1970-1976$ & 6 & 32.3 & 5 & Ohsako, 45 wins, 3 titles \\
$1981-1988$ & 10 & 18.8 & 11 & Tu, 58 wins, 7 titles \\
$1991-1997$ & 6 & 21.5 & 9 & Fudoh, 50 wins, 6 titles \\
$2000-2008$ & 9 & 18.4 & 5 & Jeon, 25 wins, 1 title \\
$2010-2013$ & 5 & 18.8 & 8 & Ahn, 28 wins, 4 titles \\
Total & 38 & $22.4 *$ & 51 & \\
\hline
\end{tabular}

*Weighted mean; **Career total tournament wins on the JLPGA Tour; ***Career total money titles. Source: lpga.or.jp 


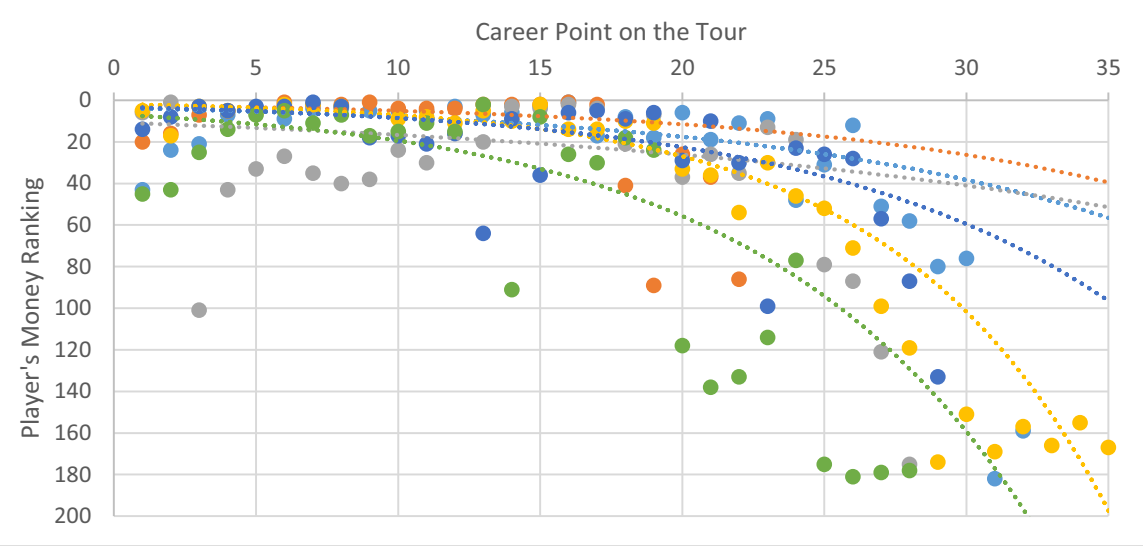

Fig. 2 Player's money rankings by career point on the tour for the JLPGA entry cohort of 1972-1976. Source: lpga.or.jp

10 or more wins by the end of the 2019 season. Fourth, although the money ranking of individual player in each cohort may manifest some fluctuations in the course of career, the dominant pattern of the career movement was definitely downward for the players in most of the cohorts. Fifth, the extent of variations in money ranking at the late stages of players' careers is substantially greater than that at the early and middle stages of their careers. As pointed out in the previous section, this may be caused by the fact that players near the disengagement stage from the tour may have more variations in the number of tournaments they play on the tour. Some may still play on a full schedule, while others may participate in only a limited number of tournaments. Sixth, the extent of inter-cohort variations in the structure of career life cycles was generally greater than that of intra-cohort variation. However, the difference in the shape of the life cycle curves within a cohort was significant especially in the case of the late stage of a player's career. In any case, the cohort analysis

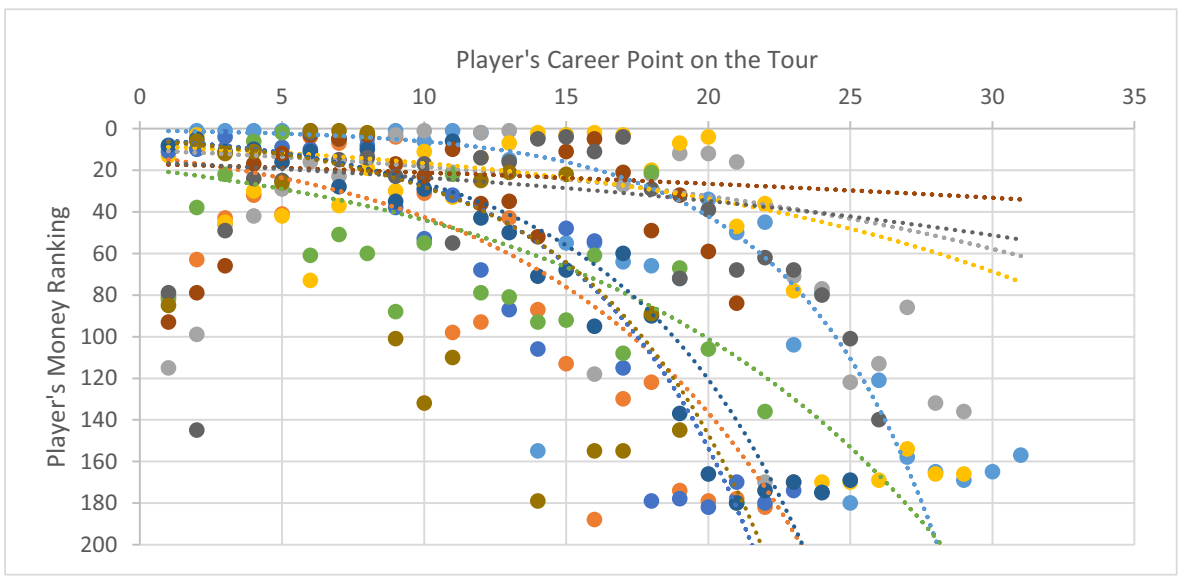

Fig. 3 Player's money ranking by career point for the JLPGA entry cohort of 1981-1988. Source: lpga.or.jp 


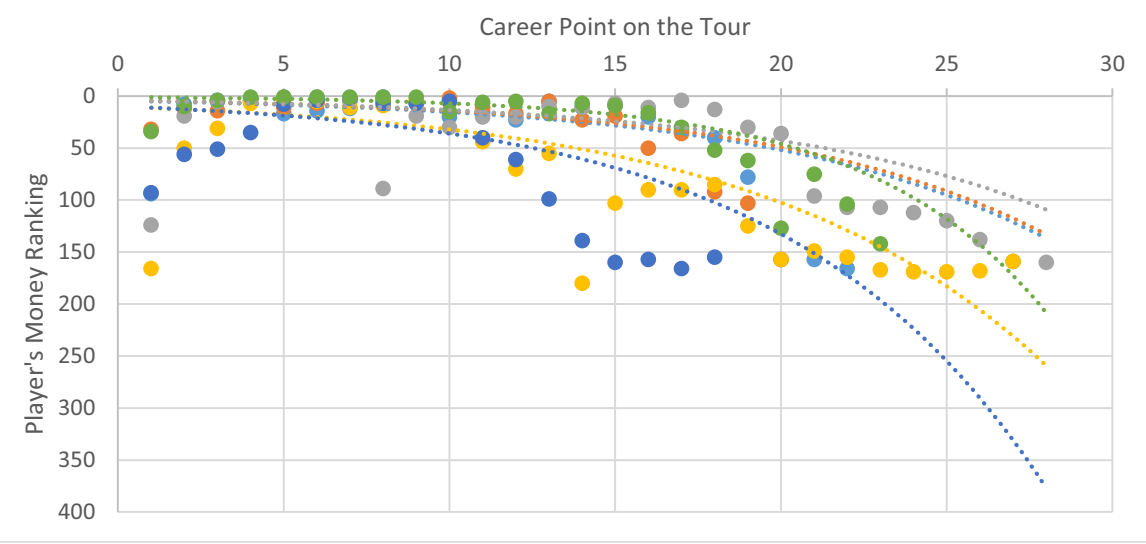

Fig. 4 Player's money ranking by career point on the tour for the JLPGA entry cohort of 1991-1997. Source: lpga.or.jp

revealed some important features of career life cycle stages which were hidden behind the aggregated clusters of the heights and breadths of the career life cycle curves for the entire player group without considering the entry cohort designation. Thus, the cohort analysis would be a valuable method of investigation when the research question involves both the cross-sectional and longitudinal variations in the athletes' career life cycles.

\section{Discussion}

It was found that only 8 players had a tournament win in their rookie season on the JLPGA Tour in the past 53 years. The time span between the first and the last tournament win in the player's career for the earlier cohorts was longer than that of

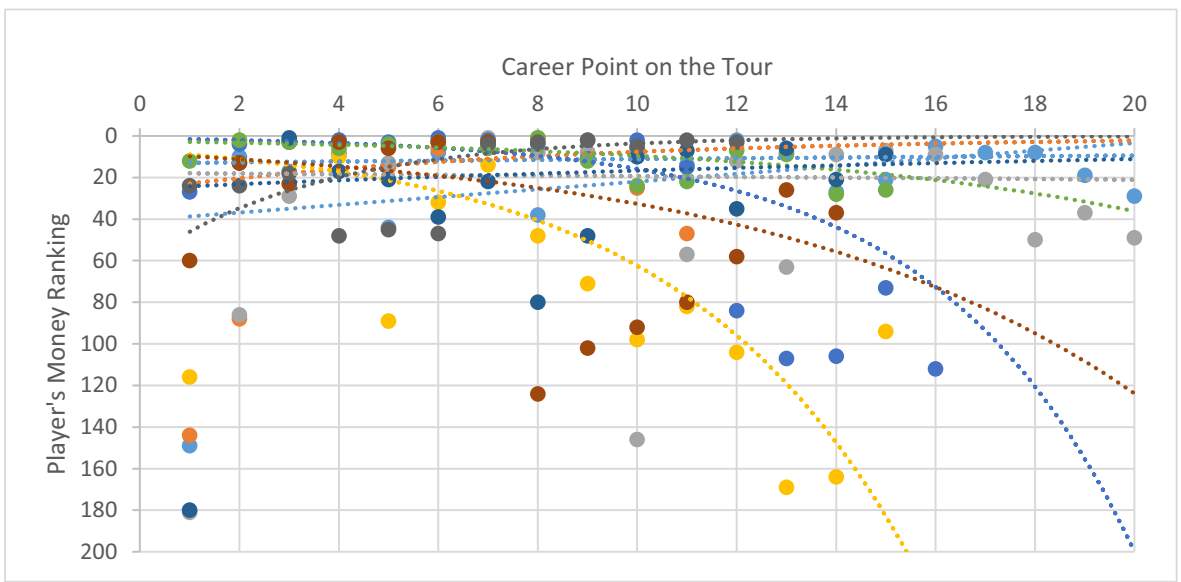

Fig. 5 Player's monkey ranking by career point on the tour for the JLPGA cohort of 2000-2008. Source: lpga. or.jp 


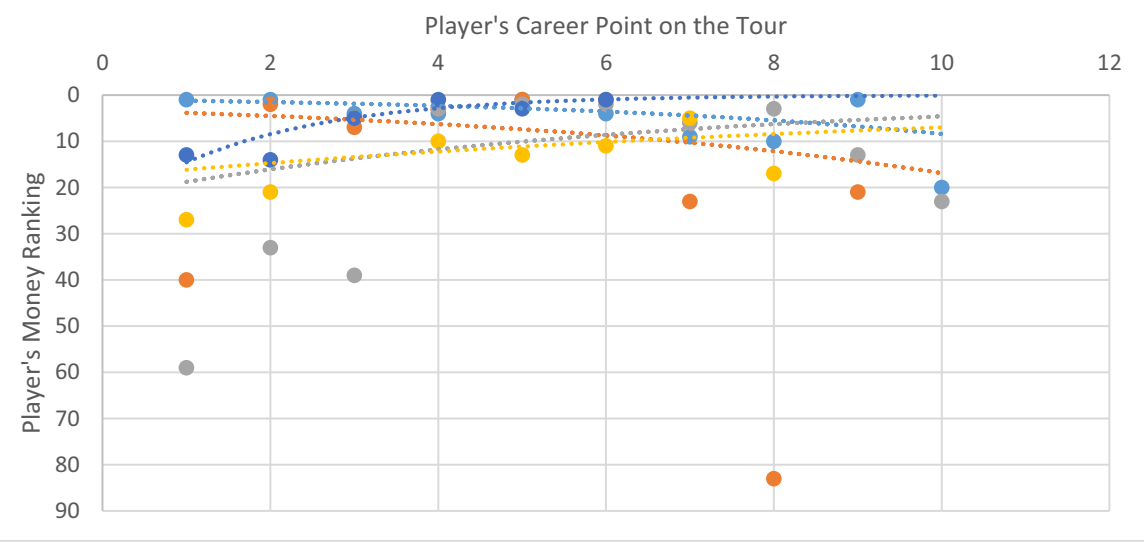

Fig. 6 Player's monkey ranking by career point on the tour for the JLPGA entry cohort of 2010-2013. Source: lpga.or.jp

the recent cohorts. This finding may suggest that the tour has become increasingly more competitive than ever before in that the rising level of competition on the tour has had a negative impact on the career durability of the tour players. It was suggested that one of the possible causes of the rise in the competition level on the tour may be the increasing influx of international players into the JLPGA Tour.

The distribution of the total career victories by the player's life cycle stage was examined. The results showed that 19 of the 38 selected players had the largest number of tournament wins during the second 5-year period, while 11 players won more tournaments during the first 5 -year period and the number of tournament wins during the third 5-year period was the largest for 6 players. From this finding, it was inferred that the "broad-peak" was more prevalent than the "early-peak" in terms of the player's performance in the career life cycle stages. Ten of the 38 elite players who had 10 or more victories on the JLPGA Tour were foreign-born players, four from Taiwan and six from Korea. The international players were concentrated in the early-peak category. The international players had a substantial playing experience on the professional tour in their home country before joining the JLPGA Tour and they had won numerous tournaments on the tour in their country. From the perspective of the career life cycle model, the international players entered the initiation stage after having a valuable professional experience in the preparation stage of their careers.

In addition to the tournament victories, the official money titles and money rankings of the JLPGA Tour were considered as the measures of performance level on the tour. Nearly two-thirds of the total number of official money titles on the JLPGA Tour over the last 53 years were secured by the players who were in their 7 th or less seasons on the tour at the time point when they won the money title. The range of variation in the money rankings in the rookie season of the players was substantial. The extent of variation tended to decline afterwards and the players were clustered around the 50th or better in the money rankings between the 3rd and 9th seasons on the tour. By around the 18th season of the players' tour career, one half of the players reaching that stage would be split into two groups, below 50th and above 50th. The foreign-born players tended to be more clustered at the upper portion of the money ranking scale than the 
Japanese players. The overall pattern of decline in money ranking from the early to late stage of player's career life cycle turned out to be quite similar.

A cohort analysis showed that at a given player's career point on the tour the younger cohorts tend to show less variations in the money ranking than the older cohorts. In each cohort, the extent of variations in money ranking at late stage of player's career found to be substantially greater than that at the early and middle stages of their careers. The extent of difference between cohorts in the structure of the career life cycles was generally greater than that of intra-cohort variation. However, the difference in the shape of the life cycle curves within a cohort was significant especially in the case of the late stage of a player's career.

Previous studies documented that women's careers are interrupted due to marriage and childbearing [29]. An investigation of the effects of marriage and childbearing on the careers of the players on the JLPGA Tour would have been an extremely valuable contribution to the body of knowledge on the career life cycles of female professional athletes. The necessary data for such an analysis were not available. Some fragmentary information on the player's marital and family status suggests that the players tend to delay their marriage and childbearing until the late stage of their career or after retirement from the tour.

Many professional athletes' careers are impacted by sports-related and nonsportsrelated injuries [17-19]. This study did not consider how the careers of the players on the JLPGA Tour are affected by injuries due to a lack of the appropriate data. A close examination of the data on the prize money rankings of the individual player disclosed that the money ranking information was missing for 1 year in a late stage of the careers of five players. It may have been due to data entry errors. In the entire careers of the 38 selected players considered in this study, there was no noticeable interruption. It is remarkable that these players have had such resilient careers during a fairly long career span. It was possible to detect a precarious side to the careers of the players. However, 19 of the 38 players experienced a decline of 50 or more in money ranking from one season to the immediately following season for multiple times in their careers. It may take both detailed and personal information from each of the players to discover the underlying causes of the downward move on the player's performance on the tour.

A great majority of the players who are either retired or still active on the JLPGA Tour started their professional careers immediately after completing their high school education. It would be extremely rare to find any player who obtained a college education as a student athlete. Turning professional at a young age may offer an advantage in that an individual may concentrate on the career route of her chosen field as early as possible. In light of the relatively short career durability of the players as well as the instability of the players' careers on the tour, not having any college education would circumscribe the possible career choices that may be available for them after their tour career ends. By offering strong inter-collegiate competition programs in golf, the student athletes would not only acquire the college-level education in a chosen academic field but also gain the experience of competitive golf in preparation for the professional careers in golf after their college experience. In the USA, nearly $10 \%$ of admission slots at top universities are for recruited student athletes. Japanese universities may consider adopting the American college admission model. But given the very stringent college admission system in Japan, it would be difficult for high school athletes to secure admissions to the colleges of their choice. One possible 
alternative would be for the JLPGA Tour to make an arrangement with selected colleges and universities to offer special continuing education programs for the tour players during the off season.

The recent trend of the golf industry in Japan has shown that Japan was no exception to the worldwide trend of the decline in the popularity of golf. Owing to the 20-yearlong economic recession between 1990 and 2010, the golf playing population shrank by more than $40 \%$ and numerous golf courses went bankrupt. The initiation fees for some exclusive private golf clubs dropped to nearly one-tenth of what they were. In particular, the Japan Golf Tour Organization (JGTO), the men's professional golf tour of Japan, has experienced a substantial reduction in the total purse as well as the total number of official tournaments in recent years. For the JGTO, the total purse was $\$ 30.26$ million with 25 official events for the 2020 season, while the JLPGA Tour's total purse was $\$ 36.54$ million with 37 official events for the 2020 season.

It is striking that the JLPGA Tour has sustained growth as a professional sports organization despite the fact that there was a serious economic recession and its men's counterpart was going through a downward spiral. The JLPGA Tour has been more effective in packaging its "product" (tournaments) as entertainment for consumers than the JGTO has. JLPGA Tour players demonstrate a high level of playing skills in golf, but they also exhibit greater popularity from the perspective of fans. It may be a case of an icing on the cake. However, women's professional sports organizations and the mass media, especially the television networks that present the live coverage of the sports events, are on the dangerous ground that may lead to the exploitation of the athlete's physical attractiveness. The foremost task of the media coverage of the sports events should be an accurate, fair, and professional reporting of the athletes' performance on the playing field. Any oblique verbal commentaries and visual presentations on the players' physical appearances may have a harmful effect on the wholesome development of the sports.

It is truly regrettable that the 2020 Summer Olympics in Tokyo, Japan, had to be rescheduled to July of 2021 due to the COVID-19 pandemic. ${ }^{36}$ The Tokyo 2020 Summer Olympics would have reinvigorated the sports industry in Japan, including the JLPGA Tour. To be sure, Japan has historically produced numerous outstanding world class women golfers. But in light of the size of the total purse and number of official tournaments of the JLPGA Tour, there is room for improvement in terms of international recognition of Japanese players. More specifically, as of March 16, 2020 only three Japanese players are ranked in the top 50 of the Rolex Women's World Golf Ranking: Nasa Hataoka at 4th, Hinako Shibuno at 12th, and Ai Suzuki at 14th. If the 2020 Summer Olympics in Tokyo were held as originally scheduled, the top 15 in the Rolex Women's World Golf Ranking as of June 29, 2020, would have qualified with a limit of four golfers per country. Japan would have one extra player on the roster of the qualified player as the host country. Hataoka is only 21 years old, but she has six victories on the JLPGA Tour already and three tournament wins in just

\footnotetext{
36 The JLPGA Tour's tournament schedule has been impacted by the COVID-19 pandemic. As of October 30, 2020, the JLPGA Tour has canceled 24 of 33 official events since the start of the 2020 season on March 5, 2020. It is uncertain how many of the four tournaments remaining on the schedule of the 2020 season would be actually played.
} 
2 years on the LPGA Tour. Hinako Shibuno has a record of five wins on the JLPGA Tour, and she won the 2019 Women's British Open, one of the five majors on the LPGA Tour. Ai Suzuki has a record of 18 wins on the JLPGA Tour and one win on the LPGA Tour. All three of these players are regarded as bona fide contenders for a medal at the Tokyo 2020 Olympics. If any Japanese player wins an Olympic medal, it would definitely become a significant watershed in the history of the golf industry in Japan.

Acknowledgements I am grateful to Professors Lim Hyun-Chin and Park Soo Jin at Seoul National University Asia Center for the visiting research fellowship at the center. I would like to thank three anonymous reviewers of East Asia: An International Quarterly for their helpful suggestions on the earlier version of this paper.

\section{References}

1. Super, D. E. (1980). A life span, life space approach to career development. Journal of Vocational Behavior, 13, 282-298.

2. Smither, L. (2003). Managing employee life cycles to improve labor retention. Leadership and Management in Engineering, 3(1), 19-23.

3. Baillie, P. H. F., \& Danish, S.J. (1992). Understanding the career transition of athletes. The Sport Psychologist, 6, 77-98.

4. Lavallee, D. (2005). The effect of a life development intervention on sports career transition adjustment. The Sport Psychologist, 19, 193-202.

5. Stambulova, N. (1994). Developmental sports career investigations in Russia: a post-perestroika analysis. The Sport Psychologist, 8, 221-237.

6. Wylleman, P., Theeboom, M., \& Lavallee. D. (2004). Successful athletic careers. In Spielberger, C. (Ed.), Encyclopedia of applied psychology. 3 (pp.511-517). New York: Elsevier.

7. Stambulova, N., Alfermann, D., Statler, T., \& Cote, J. (2009). ISSP position stand: Career development and transitions of athletes. International Journal of Sport and Exercise Psychology, 7, 395-412.

8. Savickas, M. L. (1993). Career counselling in the postmodern era. Journal of Cognitive Psychotherapy: An International Quarterly, 7(1), 205-215

9. Brott, P. E. (2005). A constructivist look at life roles. The Career Development Quarterly, 54(1), 138149.

10. Stambulova, N., Ryba, T.V., \& Henriksen, K. (2020). Career development and transitions of athletes: The International Society of Sport Psychology position stand revisited. International Journal of Sport and Exercise Psychology, https://doi.org/10.1080/1612197X.2020.1737836 published on line, 10 March, 2020 [Online] (11 November 2020).

11. Henriksen, K., C.H. Larsen, \& Chistensen, M.K. (2013). Looking at success from the opposite pole: the case of a talent development golf environment in Denmark. International Journal of Sport and Exercise Psychology, 12(2), 1-15. https://doi.org/10.1080/1612197X.2013.853473.

12. Coupland, C. (2016). The game of (your) life: professional sports careers. In Berry, M., Skinner, J., \& Engelberg, T. (Eds.), Research Handbook of Employment Relations in Sports (pp. 231-249). North Hampton, MA: Edward Elgar Publishing, Inc.

13. Osipow, S.H. (1968). Theories of career development. New York: Appleton-Century-Crofts.

14. Caroll, G.R., \& Mosakowski, E. (1987). The career dynamics of self-employment. Administrative Science Quarterly, 32(4), 570-589.

15. Douglas, E.J., \& Shepherd, D.A. (2002). Self-employment as a career choice: attitudes, entrepreneurial intentions, and utility maximization. Entrepreneurship: Theory and Practice, 26(3), 81-90.

16. Feldman, D.C., \& Bolino, M.C. (2000). Career patterns of the self-employed: career motivations and career outcomes. Journal of Small Business Management, 38(3), 53-68.

17. Barclay, C., West, S., \& Langdown, B.L. (2011). Injuries patterns among professional golfers: an international survey. British Journal of Medicine, 45(2) https://doi.org/10.1136/bjsm.2010.081554.12 [Online] (11 November 2020). 
18. McCaroll, J.R., \& Gioe, T.J. (1982). Professional golfers and price they pay. The Physician and Sportsmedicine 10 (7), 64-70.

19. McCaroll, J.R. (1996). The frequency of golf injuries. Clinical Sports Medicine, 15(1), 1-7.

20. Guttman, A., \& Thompson, L. (2001). Japanese Sports: A History. Honolulu, Hawaii: University of Hawaii Press.

21. Tanaka Y. (1992). Gorufu to Nihonjin. Tokyo: Iwanami Shinsho.[Online] (https://neojaponisme.com/ 2011/09/12/ catalog-heritage-a-short-history-of-japanese-golf/) (11 November 2020).

22. Ivy, M. (1989). Critical texts, mass artifacts: the consumption of knowledge in postmodern Japan. In Miyoshi Masao, Miyoshi, Harootunian, H. (Eds.), Postmodernism and Japan (pp. 21-46). Durham, NC: Duke University Press.

23. Ikeda, K. (2010). Ryosai-Kembo, liberal education and maternal feminism under Fascism: women and sport in modern Japan. The International Journal of the History of Sport, 27(3), 537-552.

24. Kietlinski, R. (2011). Japanese women and sport beyond baseball and sumo. London: Bloomsbury Academic.

25. Raita, K. (1999). The movement for the promotion of competitive women's sport in Japan, 1924-35. The International Journal of the History of Sport, 16(3), 120-134.

26. Bourdieu, P. (1978). Sport and social class. Social Science Information, 17, 819-840.

27. Tomlinson, A. (2004). Pierre Bourdieu and the sociological study of sport: habitus, capital and field. In Giulianotti, R. (Ed.), Sport and modern social theorists (pp. 161-172). London: Palgrave Macmillan.

28. Berry, S.M., Reese, C.S., \& Larkey, P.D. (1999). Bridging different eras in sports. Journal of the American Statistical Association, 94(447), 661-676.

29. Kietlinski, R. (2013). Sports, motherhood, and female body in contemporary Japan. The Asian Pacific Journal/Japan Focus, 11(27), 1-17.

Publisher's Note Springer Nature remains neutral with regard to jurisdictional claims in published maps and institutional affiliations. 